\title{
Conceptual provisions for assessing the effectiveness of energy saving
}

\author{
Tatiana Saurenko ${ }^{1}$, Vladimir Anisimov ${ }^{2}$, Evgeniy Anisimov ${ }^{1}$, Irina Bagaeva 2,* \\ ${ }^{1}$ Peoples Friendship University of Russia (RUDN University), 6 Miklukho-Maklaya St, Moscow, \\ 117198, Russian Federation. \\ ${ }^{2}$ Peter the Great St. Petersburg Polytechnic University, Polytechnicheskaya, 29, St. Petersburg, \\ 195251, Russia
}

\begin{abstract}
The article discusses the conceptual provisions for assessing the effectiveness of the company's energy saving. It clarifies the concept of "energy efficiency", and the place of efficiency in the system of characteristics reflecting the quality of the company's energy management. It is shown that the efficiency is advisable to be considered as a characteristic of the targeted implementation process of the company's energy management of the relevant energy conservation measures. It reflects the degree of utilization of potential opportunity allocated for the implementation of these activities to achieve the company's energy saving goals. That is, the efficiency is only one, although very important, aspect of assessing the quality of the company's energy management. A general approach is proposed for the construction of performance indicators for the creation of models and methods of decision-making support in the process of planning energy saving measures. This approach is based on the requirements that the performance indicators should be measurable and, at the same time, reflect the goal in the name of which energy conservation measures are implemented in the company, accurately reflect the results of these measures, depending on the resources allocated for their implementation, and also consider the synergistic effects of their interaction.
\end{abstract}

\section{Introduction}

In modern economic conditions the competitiveness of a company is achieved by ensuring the required volumes and quality characteristics of products (goods and services) produced while reducing production costs [1-3]. One of the priority areas for reducing production costs is energy saving. It is a complex of organizational, economic, technical, technological and other measures aimed at reducing the cost of energy resources used by the company.

Formation of rational decisions on the implementation of these activities involves:

the establishment and representation in a measurable form of energy conservation goals; the formation of alternative solutions for the implementation of energy saving measures; forecasting the results achieved when making a decision;

\footnotetext{
*Corresponding author: alyovina@gmail.com
} 
comparison of the expected results of the implementation of alternative solutions for their effectiveness and the choice of a rational solution.

Therefore, the rationality of the decisions made and, ultimately, the possibility of achieving the goals of energy saving largely depends on the correctness of the approach to evaluating the effectiveness of alternative solutions. The problem of the formation of approaches to the evaluation of efficiency has a conceptual, methodological, methodical and instrumental aspects.

In the conceptual aspect, it is necessary to define what is meant by efficiency in general and energy saving efficiency in particular.

In the methodological aspect, first of all, it is necessary to establish how (on the basis of which indicators) it is possible to measure, or to predict the effectiveness of energy saving.

In the methodological aspect, it is necessary to carry out a constructive construction of indicators that ensure the measurement (prediction) of efficiency in certain specific conditions of the company's activity.

In the instrumental aspect, it is necessary to develop appropriate software and hardware tools for predicting and estimating the efficiency of energy saving.

This article discusses the conceptual aspects of the problem of estimating the efficiency of energy saving that form the basis for the formation of indicators, models and software and hardware tools for forecasting and evaluating the effectiveness of energy saving in the interests of developing rational decisions in the company's energy management processes.

\section{The essence and place of the concept of "efficiency" in the system of concepts that reflect the quality of processes}

In the scientific literature, you can find dozens of options for the definition of the concept of "effectiveness." However, many authors use this term without the necessary explanation and refer it to various properties of the systems under consideration [4-8]. So in most works on economics, the concepts "effect" and "efficiency" do not differ. Often the "efficiency" is defined as a more general concept than "quality" (efficiency includes quality as an integral part). In other research papers the concepts "efficiency" and "quality" are considered synonymous. Thirdly (mainly philosophical) - "quality" is considered as a more general concept, including "efficiency".

Such a variety of approaches to the definition of the concept "efficiency" is naturally transferred to the research of the issues of evaluating the efficiency of energy saving, creating various indicators of its assessment. These indicators are often postulated without regard to their relationship, place and role in the overall system. And the difference in conceptual provisions, which form the basis of their constructive presentation, does not allow implementing a systematic approach in solving problems of energy saving management.

Thus, the formation of the concept "efficiency" and the creation of the concept of evaluating of efficiency is currently one of the important problems of improving the energy management of a company.

The formation of the concept "efficiency" is associated with the establishment of its relationship with related concepts, in particular, with widely used in scientific practice categories: "quality", "effect", "efficiency" and others. The establishment of this relationship, first of all, is based on the allocation of a class of systems in respect of which the concepts "effect" and "efficiency" make sense. Such a class, in our opinion, consists of the only purposeful material systems. This is the first difference between the categories "effect", "efficiency" and "quality", since systems of any nature have qualitative certainty.

Further, "effect" and "efficiency" characterize purposeful material systems only in relation to their functioning, that is, they are characteristics of action. Moreover, they do not characterize any, but only controlled processes in systems. Moreover, they characterize the 
indicated processes not as a whole, but only with regard to the conformity of their results with the goals set. This is the second significant difference in the categories "quality", "effect" and "efficiency", since quality characterizes systems in all respects, including with regard to effect and the effectiveness of their functioning.

Thus, efficiency is not the quality of targeted processes (and much less of systems) as a whole, but only one, although an important component of it. In this regard, to define the concept "efficiency", it is necessary to establish its relationship with other components of the quality of targeted processes in general and, in particular, energy-saving control processes.

The management of energy saving, as well as any purposeful process, is characterized by dialectic interdependence of the goals to be achieved, the means used to achieve the goals, methods of using the available means and the results (effect).

The structural scheme of such interdependence can be represented in the form of a directed graph shown in Fig. 1.

With regard to energy management, means can be interpreted as resources available to the company for the implementation of organizational, economic, technical, technological and other energy saving measures.

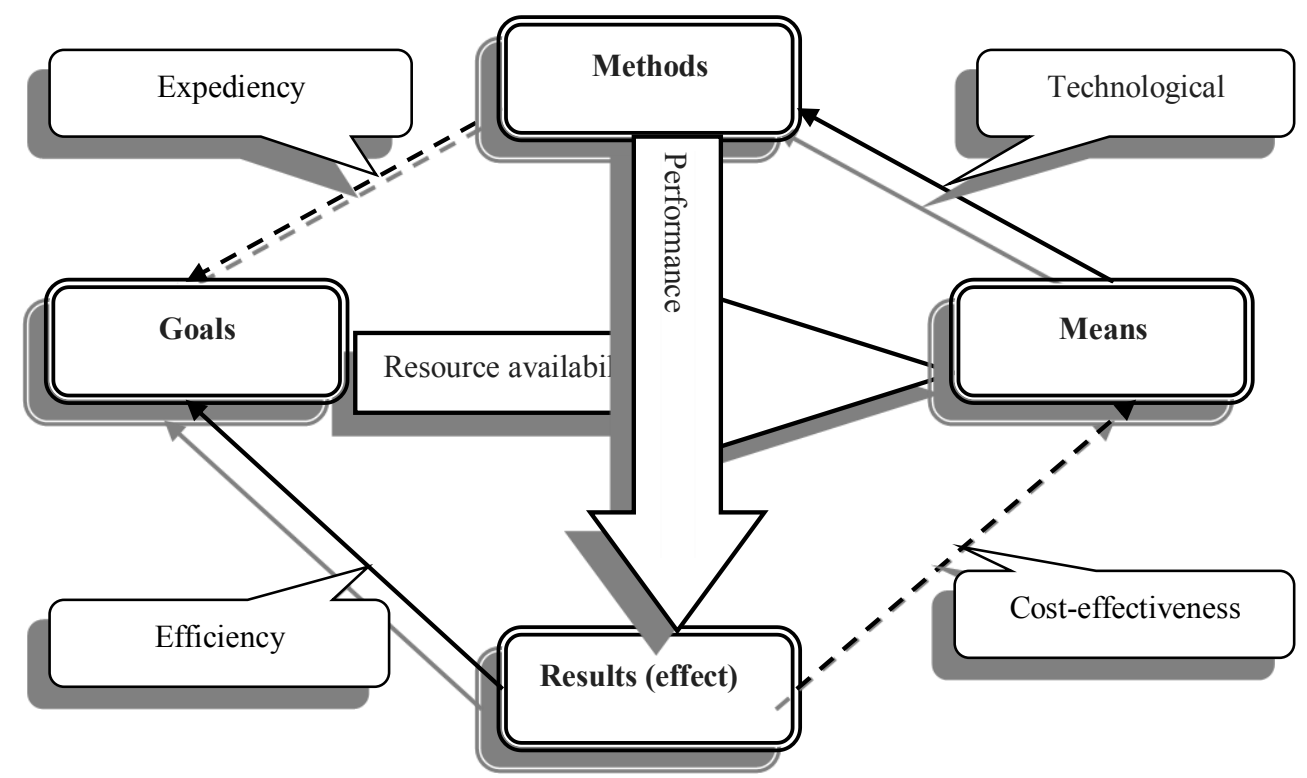

Fig. 1. Diagram of the interdependence of goals, means, methods of their use and the results achieved in the management of targeted processes.

With regard to energy management, the means can be interpreted as resources available to the company for the implementation of organizational, economic, technical, technological and other energy saving measures.

Methods characterize the established order of use of these resources.

The results reflect the energy saving effect achieved by using available resources.

With this structuring, the quality of energy saving management processes can be characterized using six interrelated groups of indicators (see Fig. 1):
1) resource availability;
2) technological;
3) performance;
4) efficiency;
5) cost-effectiveness;
6) expediency. 
Indicators of resource availability characterize the sufficiency of available resources to achieve the goals.

Technological indicators characterize the correspondence between the applied means and the methods of their use to obtain the required results.

Performance indicators characterize the results of the use of available funds in established methods.

The efficiency indicators characterize the degree of realization of the capabilities of the available resources to achieve the company's energy saving goals.

Cost-effectiveness indicators reflect the "cost" of resources to obtain results (effect). Moreover, the "cost" in the definition of profitability is interpreted in an expanded sense and includes monetary value only as a special case.

The expediency indicators characterize the correspondence between the chosen methods and established goals.

In this system of indicators the concept "quality" returns its original content, which goes back to the philosophical tradition. Efficiency becomes only one, although very important, aspect of quality assessment - a characteristic of a purposeful process of the system's functioning.

Such an approach makes it possible to understand the far from conscious fact that the target system can be, for example, efficient, but not profitable, non-technological, etc.

The essence of the concept of "efficiency" and its relationship with the concepts of "effect" and "efficiency" can be illustrated using Fig. 2. In accordance with it, the S0 company at every moment of time $t$ forms the energy saving target $(G)$ for the S1 energy supply system and allocates the corresponding resources (Ra), some of which (R1) are scarce. The energy management subsystem, based on the goals $(G)$ and the situation $(P)$, forms the energy saving measures $(\mathrm{U})$ for the $\mathrm{S} 1$ system

$$
U=U\left(G, R_{1}, R_{a}, P, t-\tau\right),
$$

where $\tau$ is the reaction time of the energy management.

The obtained results $W\left(R_{1}, R_{a}, U, P, t\right)$ include useful, from the point of view of achieving goals $G$ of energy saving of the company $S^{0}$, the results (effect) $W^{*}\left(R_{1}, R_{a}, U, P, t\right)$ and costs $-W_{L}\left(R_{1}, R_{a}, U, P, t\right)$. Taking into account the accepted notation, the essence and interrelation of the notions "effect", "efficiency" formally reflect the relations (2) - (3) in Fig. 2. 


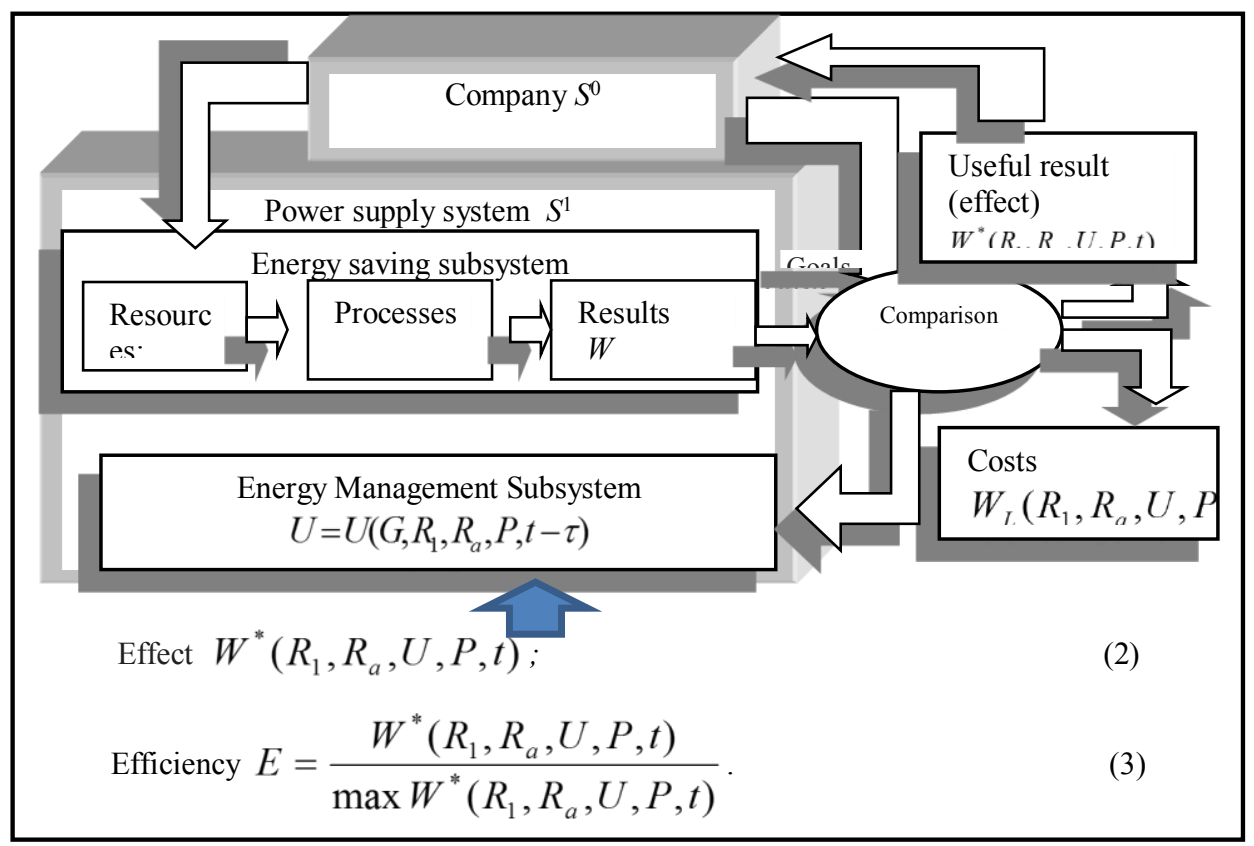

Fig. 2. The essence of the concept of "effectiveness" and its relationship with the concept of "effect".

Based on these relationships, it is possible to suggest the following definition of the concept of "effectiveness" in relation to the company's energy management processes. The efficiency of the company's energy management is a characteristic of the degree of realization of the potential capabilities of the available resources to achieve the goals.

Formally, efficiency (3) is expressed by the ratio, obtained in accordance with the decision (control action $U$ ) of the effect from the use of available resources, to the maximum possible effect when used in the prevailing conditions of the situation. From this definition, it follows that the "efficiency" of energy-saving processes, although connected with the "effect" (2) obtained as a result of the use of resources, is not limited to it.

The degree of correctness obtained on the basis of the relation (3) estimates of the effectiveness of decisions taken depends on its constructive presentation [9 - 14].

Quantitatively, the degree of realization of a company's potential for energy efficiency, as a rule, is formally represented as points of a certain efficiency scale.

As such a scale, a man most often uses the subsets of the set of real numbers (absolute scale) are most often used, and for stochastic processes, its type is the probability scale. This is explained by the convenience of numerical scales, as well as their universality, since any scale can be one-to-one transformed into a numerical one.

The display (3), which sets in correspondence to each result of the functioning of the system, the item of the chosen efficiency scale, is usually called the performance indicator.

The constructive presentation of the performance indicator is primarily connected with a clear definition of the company's energy saving goals. The goal is achieved by the rational allocation of resources between energy conservation measures.

The result is obtained during the implementation of the complex of these measures depends on the results of each individual event. It can be formally represented by the $Q$ function of particular results:

$$
W=Q\left[w_{j}\left(R_{j}\right)\right], \quad j=1,2, \ldots, J,
$$

where $w_{j}\left(R_{j}\right)$ is the result of the implementation of the $j$-th event; 
$R_{j}$ - resources allocated for the implementation of the $j$-th event;

$J$ - the number of possible measures to ensure energy saving.

Based on this, the goal of energy management is formally to maximize the display (4), with restrictions on the allocated resources.

The extent to which resources are used to achieve this goal (that is, energy efficiency) is determined by the ratio

$$
E=\frac{Q\left[w_{j}\left(R_{j}\right)\right]}{\max _{R} Q\left[w_{j}\left(R_{j}\right)\right]},
$$

where $R=\{R j\}, j=1,2, \ldots, J$ is the resource allocated for the implementation of energy saving measures.

The denominator of this expression with a fixed resource is a constant value. Consequently, in the interest of comparing different solutions when managing a company's energy savings, it is sufficient to calculate the corresponding values of the numerator of the expression in question, that is, the values of the function (4).

Thus, the construction of indicators of energy efficiency is the constructive representation of the function (4). Its constructive presentation is connected with the solution of two problems:

1) determination of the results of the implementation of individual energy saving measures, that is, a constructive representation of the values of $w j(R j), j=1,2, \ldots, J$;

2) determination of the results of energy management as a whole, that is, a constructive representation of the function $\mathrm{Q}$ (.).

The solution to the first problem is related to the specifics of energy resources and energy saving measures. When solving the second problem, one should take into account the synergistic effects of joint application of various energy saving measures.

\section{Conclusion}

In view of the above, we formulate the main postulates that define the essence of the concept "efficiency" and the purpose of its introduction to the theory and practice of energy saving management.

a) Efficiency is a characteristic of the targeted implementation process of the company's energy management of the relevant energy-saving measures.

b) Energy efficiency is emerged only when the actual implementation of these energysaving measures.

c) The main factor generating the effectiveness of the targeted process of implementing energy-saving measures is management.

d) The implementation of energy-saving measures of the company and giving this process focus are provided by the allocation of appropriate resources.

e) Energy efficiency reflects the degree of use of the potential of these resources to achieve the goal.

f) Efficiency is measurable. Measure for its measurement is determined by established indicators.

g) Indicators of efficiency should:

reflect the goal of energy saving in the company;

with necessary accuracy to reflect the results of the implementation of energy saving measures;

depend on the cost of resources for the implementation of the evaluated activities. 
h) The effectiveness of each particular process can only be correctly assessed based on an analysis of its contribution to achieving the goal of energy saving in the company as a whole. i) Measuring efficiency is not a goal, but a means of building a version of a plan for the implementation of energy-saving measures of the company.

\section{References}

1. T. Saurenko, E. Anisimov, V. Anisimov, A. Levina, MATEC Web of Conferences: International Science Conference SPbWOSCE-2017 "Business Technologies for Sustainable Urban Development", 01038 (2018)

2. V.G. Anisimov, E.G. Anisimov, T.N. Saurenko, M.A. Sonkin, Journal of Physics: Conference Series 803(1), 012006 (2017) doi.org/10.1088/1742-6596/803/1/012006

3. V. Anisimov, A. Chernysh, E. Anisimov, E3S Web of Conferences: "High-Rise Construction, HRC 2017, 03003 (2018)

4. R. Cool, R. Bruel, Energy bulletin 4, 23-37 (2009)

5. I.G. Akhmetova, L.R. Mukhametova, A.N. Bogdanov, L.A. Bagautdinova, Bulletin of Kazan State Energy University 3(18), 26-37 (2013)

6. K.K. Yumkell,a Energy bulletin industrial energy efficiency policy guidelines 4, 4-8 (2009)

7. I.V. Gentsler, E.F. Petrova, S.B. Sivaev, Energy saving in a multi-family house (Scientific book, Tver, 2009)

8. G. Ya. Vagin, L. V. Dudnikov, Methods of conducting energy audits (energy audit) of educational institutions (NSTU, N. Novgorod, 2009)

9. V.G. Anisimov, Ye.G. Anisimov, USSR Computational Mathematics and Mathematical Physics 29(5), 238 - 241 (1989)

10. E.G. Anisimov, V.G. Anisimov, M.A. Sonkin, Proceedings of the 2016 Conference on Information Technologies in Science, Management, Social Sphere and Medicine (ITSMSSM 2016). "ACSR: Advances in Computer Science Research", 282-285 (2016)

11. V. Anisimov, E. Anisimov, M.A. Sonkin, International Journal of Applied Engineering Research 10(17), 38127-38132 (2015)

12. A. Dubgorn, I. Zaychenko, N.A. Grashhenko, MATEC Web of Conferences 170, 010562017 (2018)

13. A.V. Kozlov, E.V. Rytova, S.S. Gutman, I.M. Zaychenko, 2016 XIX IEEE International Conference on Soft Computing and Measurements (SCM), 545 - 547 (2016)

14. I.M. Zaychenko, I.V. Ilin, A.I. Lyovina, Proceedings of the 31st International Business Information Management Association Conference (IBIMA), 4652-4659 (2016) 